\title{
SISTEMA MULTIMÍDIA DE APOIO À DECISÃO NA PRODUÇÃO DE LEITE E QUEIJO COALHO COM SEGURANÇA ALIMENTAR
}

\author{
JOSÉ FERNANDO MOURÃO CAVALCANTE* \\ NÉLIO JOSÉ DE ANDRADE** \\ CÉLIA LÚCIA LUCES FORTES FERREIRA** \\ MAURO MANSUR FURTADO*** \\ CLÁUDIA LÚCIA DE OLIVEIRA PINTO****
}

O objetivo deste trabalho foi disponibilizar Sistema Multimídia de Apoio à Decisão na Produção de Leite e Queijo Coalho com Segurança Alimentar, visando à melhoria da qualidade da produção das pequenas queijarias artesanais da região Nordeste do Brasil. O sistema é composto de software, denominado Coalho Quality, o qual foi avaliado por meio de questionário específico por 30 julgadores, sendo os dados analisados por métodos estatísticos descritivos, considerando-se as frequências e as porcentagens das notas atribuídas para cada atributo avaliado pelos julgadores. Concluiu-se que o Software Multimídia Coalho Quality pode ser utilizado como valiosa ferramenta de treinamento por facilitar a difusão do conhecimento e informações de técnicos especialistas. Além disso, possibilita a difusão do conhecimento para não especialistas em outras regiões longínquas do Brasil.

PALAVRAS-CHAVES: SISTEMA MULTIMÍDIA; PROCESSO DECISÓRIO; QUEIJO COALHO; SEGURANÇA ALIMENTAR.

* Professor Adjunto, Universidade Estadual do Ceará (UECE), Fortaleza, CE, Brasil (e-mail: jfmourao@uece.br).

** Professores Titular, Departamento Tecnologia de Alimentos, Universidade Federal de Viçosa (UFV), Viçosa, MG (e-mail: nandrade@ufv.br; e-mail: clferrei@ufv.br ).

*** Professor Adjunto, Departamento de Tecnologia de Alimentos, UFV, Viçosa, MG (e-mail: mmansur@ufv.br).

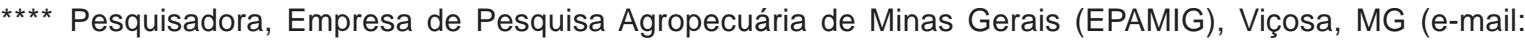
clucia@epamig.ufv.br). 


\section{INTRODUÇÃO}

O queijo coalho artesanal, produto típico da região Nordeste, tem grande aceitação popular e representa fonte de renda e trabalho para parcela considerável de pequenos e médios produtores rurais. Entretanto, diversos trabalhos de pesquisa relatam que a qualidade microbiológica desse queijo constitui risco à saúde do consumidor (PIRES et al., 1994; MORAIS, 1995; SENA, 2000; ESCOBAR et al., 2001; NASSU et al., 2003; NETO et al., 2004; TESHIMA et al., 2004). Esse fato se deve, principalmente, às precárias condições higiênico-sanitárias na obtenção do leite na fazenda, às deficiências estruturais existentes no processamento das pequenas queijarias e à falta de conhecimentos técnicos sobre higiene e microbiologia de alimentos dos responsáveis pela sua elaboração.

O sucesso na produção do queijo coalho artesanal com qualidade depende da qualificação do ser humano, que deve receber treinamento e capacitação para as atividades que vai executar. Além disso, deve ter consciência da importância de seu papel em relação a todo processo e responsabilidade sobre os atos que praticar. $\mathrm{O}$ treinamento constitui processo educacional, aplicado de maneira sistemática e organizada, por meio do qual a pessoa adquire conhecimentos, atitudes e habilidades de acordo com objetivos definidos (DRESCH e JONG, 2002).

O treinamento distingue-se da educação formal, principalmente em relação aos objetivos desejados. Enquanto a educação desafia intelectualmente o indivíduo, que descobre habilidades e talentos latentes e incrementa o desempenho do agir e pensar, o treinamento ensina capacidades ou procedimentos específicos (CHIAVENATO, 1985).

O Sistema Multimídia pode ser definido como o programa de computador que permite ao usuário criar e manter conjuntos de informações, interligados de forma não sequencial. Essas informações podem estar combinadas em diferentes formatos de apresentação como textos, imagens, vídeos, sons e animações num único sistema multimídia sob a forma digital (MAURER, 1993).

Na Figura 1 é apresentado um fluxograma de treinamento, visto como um sistema dinâmico e contínuo.

As principais vantagens do Sistema Multimídia em educação e treinamento organizacional são: I) redução do tempo de aprendizagem; II) consistência pedagógica; III) flexibilidade; IV) maior motivação por parte do usuário quanto ao processo de aprender fazendo; $V$ ) aumento da memorização dos conteúdos em longo prazo (NEVES JR., 2002). Outra vantagem do Sistema Multimídia, embora não seja produzido com essa finalidade, é a possibilidade de treinar pessoas a usar corretamente 0 computador. Como desvantagem ou limitação do uso de Sistemas Multimídia, destaca-se o alto custo para sua produção, mas considera-se que isso possa ser minimizado pela sua durabilidade, consistência e grande número de pessoas que podem ser beneficiadas (ANTUNES, 2003).

O Sistema Multimídia, como apoio à decisão, constitui poderosa ferramenta de treinamento, proporcionando mais conhecimentos e disseminando informações de técnicos especialistas na área. Além disso, possibilita a disseminação do conhecimento por meio de programa de computador para outras pessoas ou regiões geográficas longínquas. Ao utilizar essas informações no processo de tomada de decisão, o usuário enriquece seu conhecimento sobre o assunto e pode dedicar-se a outros pontos de determinado problema. Assim, o computador pode ser utilizado como poderoso instrumento para transferência de conhecimentos e tecnologias aos agricultores (POZZA, 1998).

O objetivo deste trabalho foi disponibilizar conhecimentos científicos e tecnológicos sobre a produção de leite e queijo coalho com segurança alimentar por meio de recursos multimídia.

\section{MATERIAL E MÉTODOS}

\subsection{CONSTRUÇÃO DO SOFTWARE MULTIMÍDIA COALHO QUALITY}

Desenvolveu-se software multimídia, denominado Coalho Quality, sobre a produção de leite e 
queijo coalho com segurança alimentar, em parceria entre o Departamento de Tecnologia de Alimentos (DTA) da Universidade Federal de Viçosa (UFV) e a Consultoria e Desenvolvimento de Sistemas (Cientec), empresa de Viçosa, Minas Gerais. O desenvolvimento do Software Multimídia ocorreu em quatro etapas, conforme descritas subsequentemente.

FIGURA 1 - FLUXOGRAMA DE TREINAMENTO VISTO COMO SISTEMA DINÂMICO E CONTÍNUO

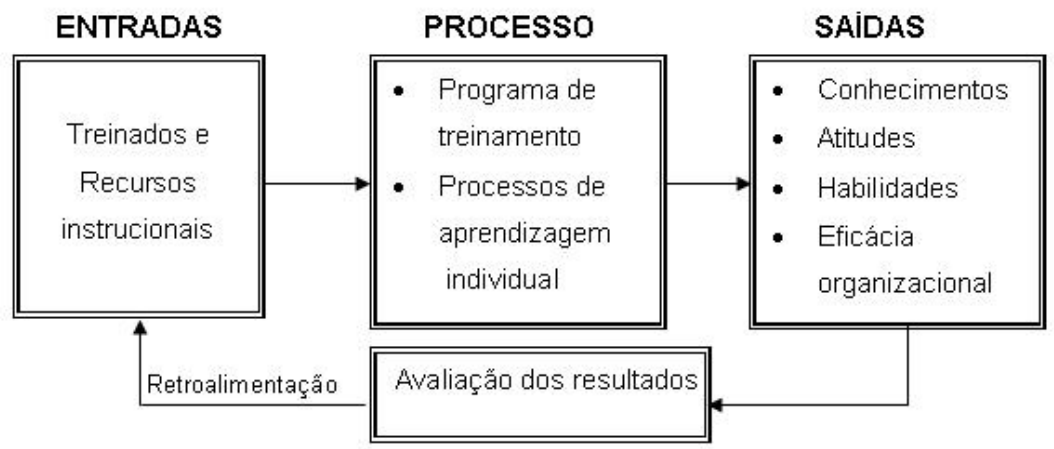

Fonte: CHIAVENATO (1985).

\subsubsection{Aquisição do conhecimento}

O conhecimento científico e tecnológico para a elaboração do software multimídia foi adquirido mediante consulta a especialistas da área, extensa revisão de literatura em livros, periódicos, internet e de outros sistemas multimídias já disponíveis, como os CD-ROM Ferramentas para implantação do sistema APPCC (SENAI, 1999); Programa alimentos seguros - ferramentas para implantação do sistema APPCC e das boas práticas (SENAI, 2002). Foram também consultados sistemas especialistas desenvolvidos na UFV, como SISTSAN (SPROESSER, 1991), ACQUA-SIST (MACÊDO, 1994), BACSIST (FREITAS, 1995), TomEx-UFV (POZZA, 1998), Sistema de apoio à decisão em colheita florestal (SANTOS, 2000) e o Sistema multimídia de apoio à decisão em procedimentos de higiene para unidades de alimentação e nutrição, denominado Clean Up (ANTUNES, 2003). Foram ainda incluídos os conhecimentos das disciplinas Tecnologia de Queijos Especiais; Microbiologia de Leite e Derivados; Processamento de Leite de Consumo; Processamento de Alimentos; Garantia da Qualidade de Alimentos; Detergentes e Sanitizantes na Indústria de Alimentos; Análise Sensorial; Tecnologia da Produção de Culturas Láticas do programa de Pós-Graduação do DTA da UFV e da experiência prática dos seus professores, pesquisadores e técnicos em laticínios. Buscou-se também informação sobre:

- cuidados higiênicos na ordenha para obtenção de leite de qualidade na fazenda (BRANDÃO, 1997; CHAPAVAL e PIEKARSKI, 2000; TRONCO, 2003);

- fatores que contribuem para a contaminação do leite, como: I) animal; II) homem; III) água; IV) utensílios: baldes, latões e filtros de pano; e V) fontes diversas, como a poeira, moscas, esterco, dentre outras (PINHEIRO e MOSQUIM, 1995; PICININ et al., 2001; PINHEIRO e SOUSA, 2004);

- importância da qualidade da água: I) limpeza de equipamentos e utensílios em queijarias; II) padrões de potabilidade: aspectos físicos, químicos e microbiológicos e suas implicações; e III) dureza da água como fator importante a ser considerado para a produção de leite de boa qualidade (ANDRADE e MACÊDO, 1996; PICININ et al., 2001);

- importância do controle sanitário do rebanho leiteiro: I) principais doenças que podem ser transmitidas ao homem por meio da ingestão do leite cru, como a brucelose e tuberculose; e II) como prevenir essas doenças (CHAPAVAL e PIEKARSKI, 2000; BRESSAN, 2000);

- problema de mastite em vacas leiteiras e suas consequências na qualidade do leite e nos produtos derivados (BRABES, 1999; SENA, 2000; BRITO, 2002); 
- procedimentos simples e eficazes de higienização de: I) equipamentos e utensílios; e II) manipuladores e ambientes de processamento de queijos (ANDRADE e MACÊDO, 1996; BRANDÃO, 1997; CHAPAVAL e PIEKARSKI, 2000);

- importância do controle de qualidade em queijos (FURTADO, 1999);

- pontos críticos de controle na produção de queijos artesanais (MORAIS, 1995; ESCOBAR et al., 2001);

- principais fatores que influenciam a qualidade do queijo: causas de defeitos e prevenção (FURTADO, 1991; FURTADO, 1999);

- informações técnicas sobre pequena fábrica de queijo coalho, incluindo: I) planta baixa; II) especificações de áreas, equipamentos e utensílios; e III) outros utensílios necessários ao bom funcionamento de queijaria artesanal (PIRES et al., 1994; YASSU, 2003);

- fabricação do queijo coalho empregando leite pasteurizado e culturas láticas endógenas, incluindo fluxograma de processamento, visando assegurar a padronização do produto final e a segurança alimentar (CAVALCANTE et al., 2004);

- legislação brasileira pertinente à produção de leite e derivados, mais especificamente, queijos (BRASIL, 1993; BRASIL, 1997a; BRASIL, 1997b; BRASIL, 1998; BRASIL, 2000; BRASIL, 2001; BRASIL, 2002).

\subsubsection{Organização do conhecimento}

Dividiu-se o conhecimento em nove módulos, conforme especificado a seguir: Cuidados higiênicos na obtenção do leite na fazenda; Fontes de contaminação do leite; Controle sanitário do rebanho leiteiro; Higienização de utensílios, equipamentos e ambientes de processamento; Importância do controle de qualidade na produção de queijos; Protocolo de fabricação de queijo coalho; Principais defeitos do queijo coalho; Planta baixa de fábrica de queijo coalho; Itens de apoio: Glossário, Saiba mais, Legislação e Links de interesse.

Ainformação foi organizada em cada módulo de forma estruturada e hierárquica. As informações mais relevantes são aquelas que interferem diretamente na qualidade microbiológica do leite e do produto final (queijo), como as informações sobre as condições higiênicas na obtenção do leite na fazenda, durante o processamento do queijo e do produto acabado e comercializado. Foram determinados os pontos em que as informações se complementam (links) para facilitar a localização do conhecimento pelo usuário do Sistema Multimídia.

\subsubsection{Desenvolvimento do Software}

Nesta etapa, foi construída a interface do Software Multimídia com base na organização do conhecimento. Foram incluídos na equipe de trabalho um programador para criar o ambiente de desenvolvimento e um programador visual para produção da identidade gráfica do sistema e edição de vídeos, fotografias e animações. Fotos, vídeos e animações ilustraram o texto para facilitar o entendimento do conteúdo. Essas mídias foram produzidas e desenvolvidas após a elaboração do conteúdo e paralelamente à construção da interface. Na produção de mídias dinâmicas foram produzidos os vídeos e as animações gráficas e na produção de mídias estáticas os textos e as imagens foram digitalizados. Utilizou-se computador Athlon XP 1,7 Mhz, 256 MB de memória RAM, monitor SVGA colorido, com placa de vídeo 3D RIVA TNT2.

O aplicativo multimídia foi criado a partir do ambiente de desenvolvimento Borland Delphi para sistemas com interface padrão Windows ${ }^{\circledR}$, utilizando a linguagem Object Pascal de programação.

Para a realização das animações, o Action Script (linguagem de programação do ambiente Macromedia Flash $M X$ ) foi utilizado devido à facilidade na manipulação de imagens vetoriais. Já no preparo das imagens foram empregados os programas gráficos Adobe Photoshop e o Corel Draw em razão de sua facilidade operacional e qualidade das imagens geradas. 
Para a montagem dos textos empregou-se o Macromedia Dreamweaver MX pela facilidade de uso e pelos códigos HTML gerados pela ferramenta.

Ambiente de programação orientado para os objetos facilitou o desenvolvimento de aplicativo multimídia, devido à sua capacidade de criar objetos, o que permite trabalhar qualquer tipo de navegação que se faça necessária para alcançar os objetivos propostos. Cada módulo abordado pode ser considerado um objeto, e, dessa forma, a informação obedece estrutura bem flexível, com diversos itens, cada um com seus respectivos subitens. Cada objeto pode ser de tipo diferente, o que permite melhor apresentação das ideias e a associação de imagem e texto na transmissão do conteúdo proposto. Esse modelo facilita a criação do roteiro, estruturação das ideias e comunicação entre os objetos de qualquer tipo (como vídeos, textos ou animações).

\subsubsection{Avaliação do Software Multimídia Coalho Quality}

No primeiro semestre de 2005 avaliou-se o software por meio da aplicação de teste de aceitação, baseado na escala Likert (TROCHIM, 2003) e elaborado para esse fim. Foram selecionados 30 usuários potenciais, incluindo professores e estudantes dos Programas de Pós-Graduação em Ciência e Tecnologia de Alimentos da UFV.

A escala Likert foi modificada com os atributos próprios da escala hedônica sugeridos por CHAVES e SPROESSER (1999). Foram escolhidos adjetivos qualificativos para identificar os intervalos dessa escala que variaram de "bom", quando o avaliador foi positivamente favorecido pela ferramenta a ele apresentada, "regular" quando o avaliador foi moderadamente favorecido e "ruim" quando o avaliador considerou que não foi favorecido pelo Sistema Multimídia. Além dos adjetivos qualificativos, foram atribuídas notas de 1 (um) a 9 (nove) aos atributos (ANTUNES, 2003).

Cada avaliador recebeu uma cópia do Software Coalho Quality acompanhada do questionário de avaliação, mostrado na Figura 2.

\section{FIGURA 2 - QUESTIONÁRIO DE AVALIAÇÃO DO SOFTWARE MULTIMÍDIA COALHO QUALITY}

Nome completo: (preencher esse campo considerado necessário). Data: ..../..............

Utilizando como referência a escala abaixo, porfavor, assinale a opção que mais se aproximou de sua opinião quanto ao tópico apresentado.

\begin{tabular}{lc}
\hline CLASSIFICAÇÃO DA ESC ALA LIKERT & ESCORE (NOT A) \\
\hline Bom & 9 \\
& 8 \\
\hline Regular & 7 \\
& 6 \\
\hline Ruim & 5 \\
& 4 \\
\hline
\end{tabular}

1) Forma de apresentação das telas

$$
1 \square 2 \square 3 \square 4 \square 5 \square 6 \square 7 \square 8 \square 9 \square
$$

2) Estética e qualida de gráf ica dos ambientes

${ }_{1} \square 2 \square 3 \square{ }_{4} \square \square{ }_{6} \square 7 \square 8_{8} \square$

3) Cores e imagens na interface

$1 \square \quad 2 \square \quad 3 \square \quad 4 \square 5 \square \quad 6 \square 7 \square \quad 8 \square \quad 9 \square$

4) Facilidade de navegação pelos ambientes por usuários não treinados

${ }_{1} \square_{2} \square_{3} \square_{4} \square_{5} \square{ }_{6} \square_{7} \square{ }_{8} \square{ }_{9} \square$

5) Legibilidade do texto

${ }_{1} \square_{2} \square_{3} \square_{4} \square_{5} \square{ }_{6} \square_{7} \square{ }_{8} \square{ }_{9} \square$

6) Qualidade das informações escrit as e mídias (fotos digitais)

${ }_{1} \square_{2} \square_{3} \square_{4} \square_{5} \square_{6}{ }_{7} \square_{8}{ }_{9} \square$

7) Abordagem do assunto "Queijo Coalho com Qualidade" no Software Multimídia

${ }_{1} \square_{2} \square_{3} \square_{4} \square_{5}{ }_{6}{ }_{6} \square_{8}{ }_{9} \square$ 
continuação

8) Sequência lógica na apresentação dos módulos
$1 \square$

9) Quantidade de informação disponível para o entendimento do assunto

$\square_{2} \square_{3} \square_{4} \square_{5} \square{ }_{6} \square_{7} \square_{8} \square \square_{9}$

10) Adequação do multimídia ao púb lico-alvo

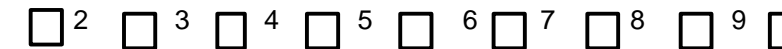

Continuação

11) Ava lie cada amb iente do Coalho Quality (nota de 1 a 9)

\begin{tabular}{|c|l|c|}
\hline Módulo & \multicolumn{1}{|c|}{ Assunto do Módulo } & Nota \\
\hline 1 & Cuidados higiênicos na obtenção do leite na fazenda & \\
\hline 2 & Fontes de contaminação do leite & \\
\hline 3 & Controle sanitário do rebanho leiteiro & \\
\hline 4 & Higienização de utensílios, equipamentos e outros & \\
\hline 5 & Importância do controle de qualidade & \\
\hline 6 & Protocolo de fabricação do queijo Coalho & \\
\hline 7 & Principais def eitos do queijo Coalho: caus as e prevenção & \\
\hline 8 & Planta baixa de uma fábrica de queijo Coalho & \\
\hline 9 & Módulo de Apoio (G lossário, Saiba mais, Legislação e Links de interesse) & \\
\hline
\end{tabular}

Questões com plementares (pode ser assinalada mais de uma opção):

Para você qual(is) benefício(s) esse sistema proporcionará como suporte na produção de queijo coalho com segurança alimentar?

a. ( ) Possibilidade de uso no processo educacional dos produt ores

b. ( ) Possibilidade de uso para treinamento de pessoal edesenvolvimento de habilidades

c. ( ) Interatividade entre extensionistas/equipe técnica/produto res

d. ( ) R ea lização de atividades cooperativas e colaborativas

e. ( ) Maior estímulo pa ra produção de le ite e que ijo coalho com qualidade

f. ( ) Outros. Quais?

Assinale as possíveis dificuldades que você constatou quando da utilização do Software Mult imídia e que os futuros usuários enfrentarão:

a. ( ) Falta de domínio do uso do computador.

b. ( ) Não entendimento do conteúdo.

c. ( ) Outros. Qua is?

Assinale as mudanças ma is significativas que você sugere para o Software Multimídia:

a. ( ) Modificações no visual da interface.

b. ( ) Modific ações na forma de apresentação do conteúdo.

c. ( ) Modificações no conteúdo propriamente dito.

d. ( ) Modificações na sequência de módulos.

e. ( ) Inclusão ou exclusão de itens, recurso s, etc.

f. ( ) Outros. Quais?

Críticas e sugestões:

\subsubsection{Análise dos resultados da avaliação do Software Multimídia}

Os dados coletados, por meio de questionário de avaliação, foram organizados e compilados. Após, construiu-se banco de dados no programa Excel, com as frequências e respectivas porcentagens das notas atribuídas para cada quesito pelos 30 avaliadores. A partir desse banco foram construídos gráficos, relacionando as porcentagens das notas atribuídas a cada quesito avaliado. Foram determinados os valores da moda e das notas máximas e mínimas atribuídas pelos avaliadores à interface, ao conteúdo e aos módulos do software multimídia. 


\section{RESULTADOS E DISCUSSÃO}

O Software Multimídia, denominado Coalho Quality, é composto de nove módulos interligados, que facilitam a compreensão e o entendimento rápido no seu uso, conforme mostra o organograma nas Figuras 3 e 4.

FIGURA 3 - ESTRUTURA BÁSICA DO SOFTWARE MULTIMÍDIA COALHO QUALITY

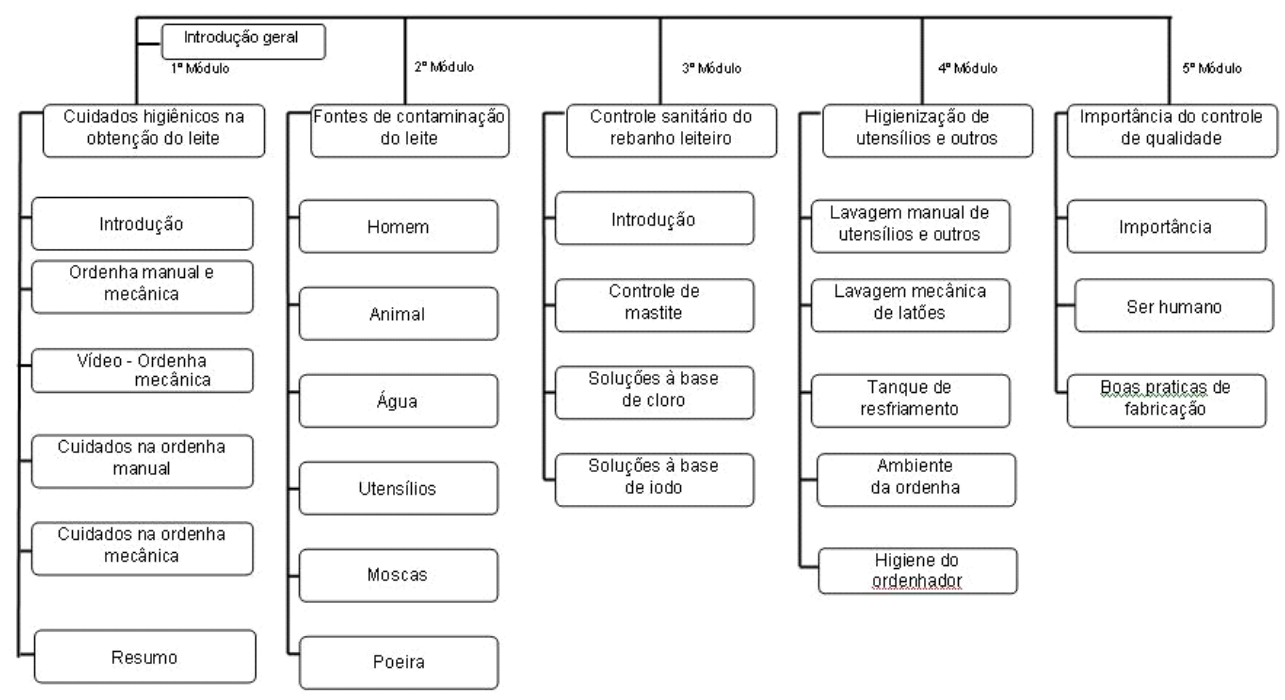

FIGURA 4 - ESTRUTURA BÁSICA DO SOFTWARE MULTIMÍDIA COALHO QUALITY

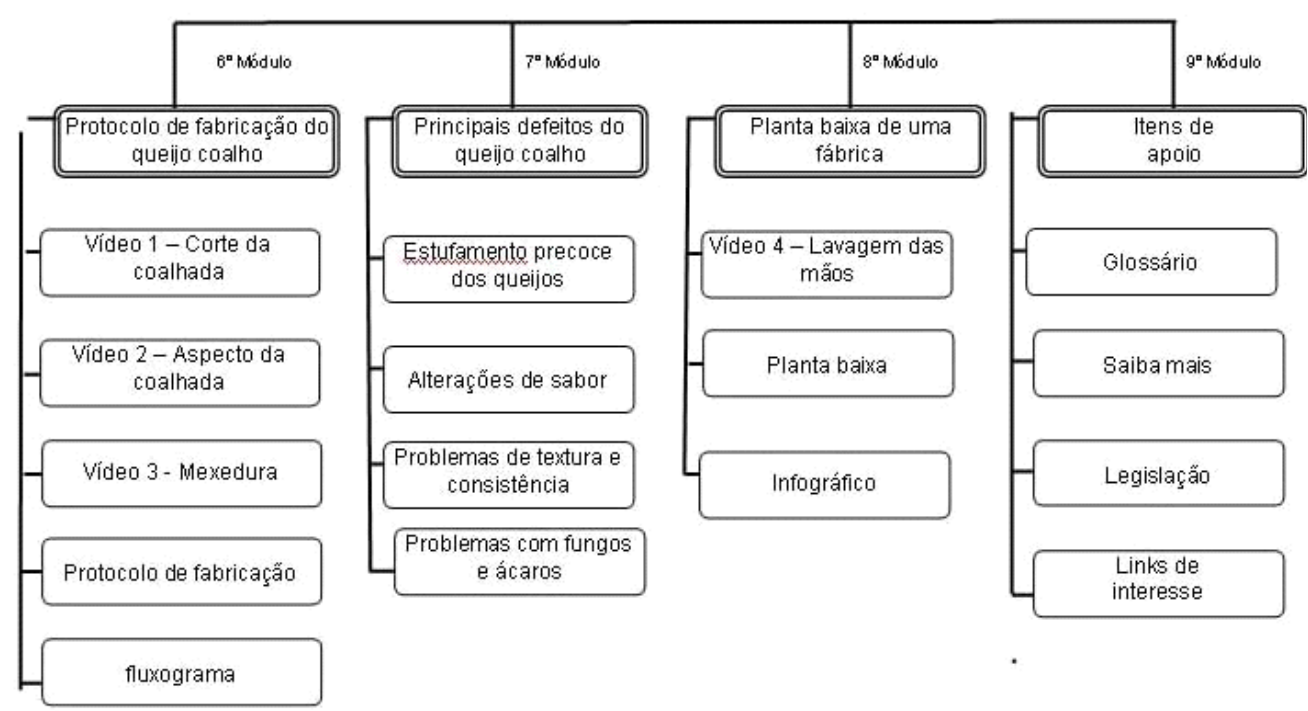

Os módulos 01 e 06 , considerados os mais relevantes do multimídia, abordam de maneira detalhada os procedimentos de higiene na obtenção do leite cru e na produção do queijo coalho. Os demais módulos fornecem informações de apoio para a tomada de decisão e o treinamento dos usuários. Nesses módulos, estão as informações técnicas e as práticas relevantes, além dos conceitos e dos procedimentos sobre a produção de leite e queijo coalho com segurança alimentar (Figura 5).

As cores claras do ambiente de processamento são predominantes, conferindo aspecto de limpeza e asseio que são os principais objetivos do Software Multimídia. Foram usadas para permitir 
ao usuário, ao deslizar o mouse sobre a tela, visualizar as imagens de fundo relacionadas ao processo de fabricação do queijo coalho. A tela inicial do Software Multimídia foi elaborada com cores mais escuras para chamar a atenção do usuário sobre a importância da maturação do queijo coalho.

\section{FIGURA 5 - TELA INICIAL DO SOFTWARE MULTIMÍDIA COALHO QUALITY}

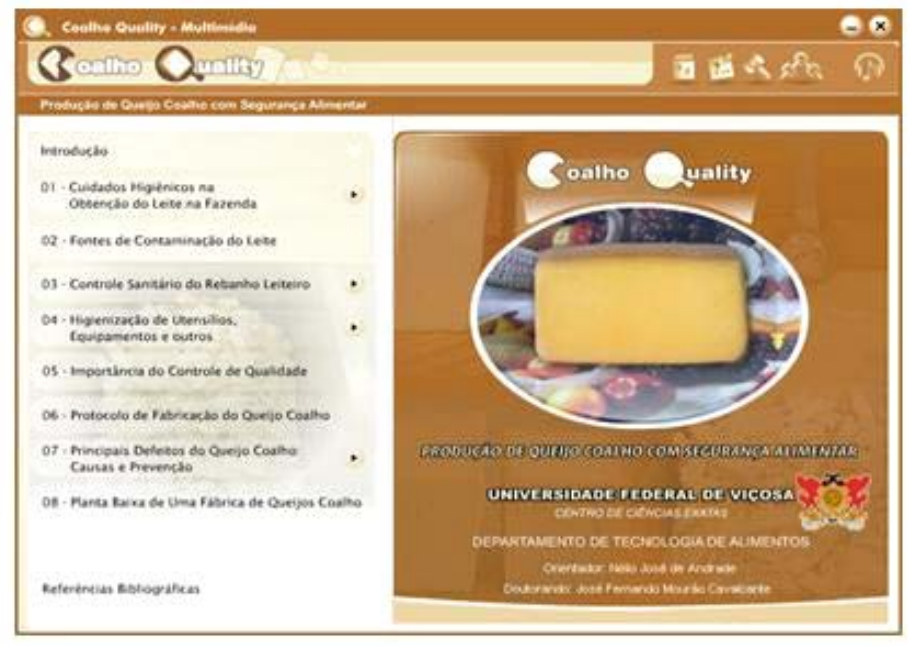

Nas Figuras 6 e 7 são apresentadas as porcentagens de frequências dos resultados das notas atribuídas às questões que avaliaram o Software Multimídia.

De acordo com os resultados mostrados nas Figuras 6 e 7, os quesitos 1, 2 e 7 foram considerados como "bom" por todos os avaliadores. Os quesitos 3, 8 e 9 foram classificados como "bom" por 96,7\% dos avaliadores e "regular" por 3,3\%. Com relação ao quesito 4, 90,0\% dos avaliadores o consideraram "bom" e 10,0\% "regular".

Os quesitos 5 e 6 foram considerados como "bom" por 93,4\% e "regular" por 6,6\% dos avaliadores. Finalmente, o quesito 10 foi considerado "bom" por $86,7 \%$ dos avaliadores, enquanto $13,3 \%$ consideraramno "regular". Os quesitos "apresentação das telas, estética e qualidade gráfica dos ambientes e a abordagem do assunto queijo coalho com qualidade" foram considerados como "bom" na escala Likert por 100,0\% dos avaliadores. Por meio dos resultados da avaliação do Software Multimídia constatou-se boa aceitação por parte dos avaliadores, indicando que o sistema pode ser útil ao público-alvo e muito auxiliará na tomada de decisão na produção de queijo coalho com segurança alimentar.

As opiniões dos avaliadores, incluindo os aspectos positivos, negativos e sugestões atribuídas ao Software Multimídia foram consideradas para melhorar a qualidade do sistema. O resumo dos aspectos mais relevantes relacionados ao Software Multimídia consta do Quadro 1.

Os resultados da avaliação dos Módulos 1, 2 e 3, considerados como "bom" por 96,7\% dos avaliadores e "regular" apenas por 3,3\% estão nas Figuras 8 e 9. Com relação ao módulo 4, 100,0\% dos avaliadores o consideraram "bom".

O Módulo 5 foi considerado "bom" por 90,0\% dos avaliadores, enquanto 10,0\% consideraram-no "regular". O Módulo 6, que trata do protocolo de fabricação do queijo coalho, alcançou o conceito "bom" por $100,0 \%$ dos avaliadores. Os Módulos 7, 8 e 9, que abordam os principais defeitos do queijo coalho, planta baixa de uma fábrica de queijo Coalho e itens de apoio (Saiba Mais, Glossário, Legislação e Links de interesse) foram considerados como "bom" por $96,7 \%$ dos avaliadores e "regular" por apenas 3,3\%.

No geral, os módulos do Software Multimídia alcançaram boa aceitação por parte dos avaliadores, indicando que o mesmo pode ser utilizado como ferramenta útil no treinamento de pessoal e no desenvolvimento de habilidades, no processo educacional dos produtores de queijo coalho, aumentando a interatividade entre extensionistas e produtores e estimulando a produção de leite e queijo coalho com qualidade e segurança alimentar. 
A interface possibilitou boa interação entre usuário e máquina, resultado indicado pelo uso do programa sem que houvesse necessidade de treinamento específico, conforme mostra a Tabela 1. Espera-se que os usuários desse multimídia sejam pessoas com conhecimento mínimo de informática. Os ambientes serão acessados pelos usuários por meio de ícones e dos próprios módulos descritos na tela inicial que sinalizam o caminho ao longo da interface. Todos os itens avaliados da interface, incluindo forma de apresentação das telas, estética e qualidade gráfica dos ambientes, as cores e as imagens na interface, a facilidade de navegação pelos ambientes por usuários não treinados e a legibilidade do texto foram classificados pelos avaliadores como "muito bom" e, ou, "extremamente bom", com exceção do item 4, classificado como "moderadamente bom".

FIGURA 6 - PORCENTAGENS DE FREQUÊNCIAS DE NOTAS ATRIBUÍDAS ÀS QUESTÕES QUE AVALIARAM OS ITENS: 1) FORMA DE APRESENTAÇÃO DAS TELAS; 2) ESTÉTICA E QUALIDADE GRÁFICA DOS AMBIENTES; 3) CORES E IMAGENS NA INTERFACE; 4) FACILIDADE DE NAVEGAÇÃO PELOS AMBIENTES POR USUÁRIOS NÃO TREINADOS; 5) LEGIBILIDADE DO TEXTO; E 6) QUALIDADE DAS INFORMAÇÕES ESCRITAS E MÍDIAS
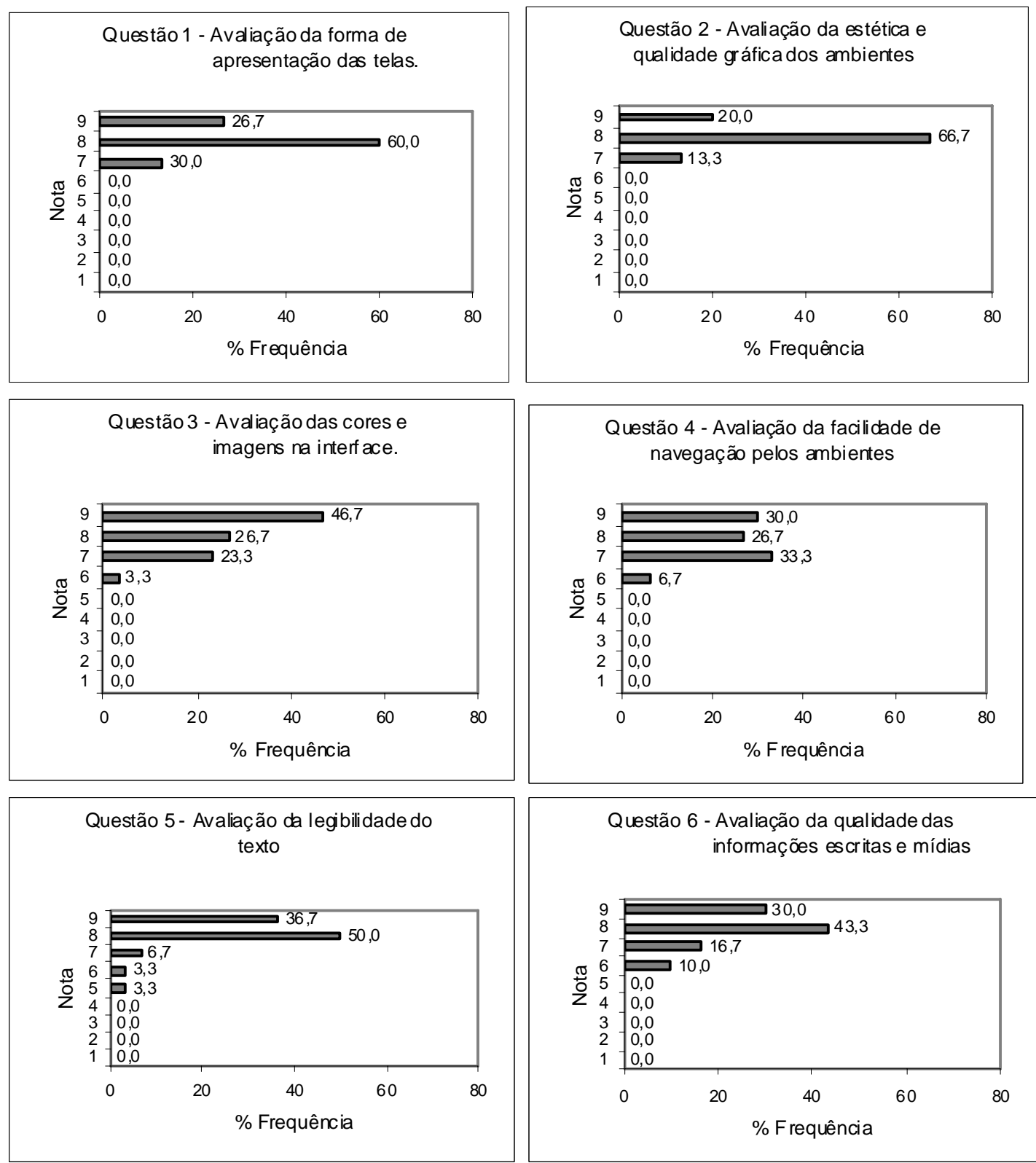
FIGURA 7 - PORCENTAGENS DE FREQUÊNCIAS DE NOTAS ATRIBUÍDAS ÀS QUESTÕES QUE AVALIARAM OS ITENS: 7) ABORDAGEM DO ASSUNTO QUEIJO COALHO COM QUALIDADE; 8) SEQUÊNCIA LÓGICA NA APRESENTAÇÃO DOS MÓDULOS; 9) QUANTIDADE DE INFORMAÇÃO DISPONÍVEL PARA O ENTENDIMENTO DO ASSUNTO; 10) ADEQUAÇÃO DO MULTIMÍDIA AO PÚBLICO-ALVO

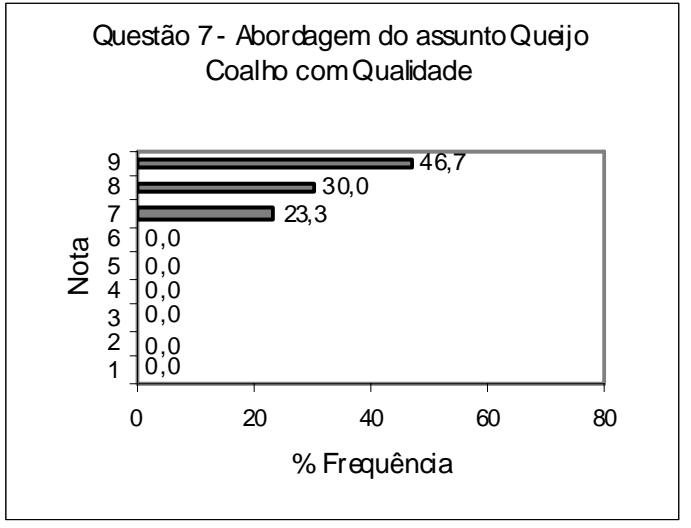

Questão 9 - Avaliação da quantidade de informação disponível para entendimento

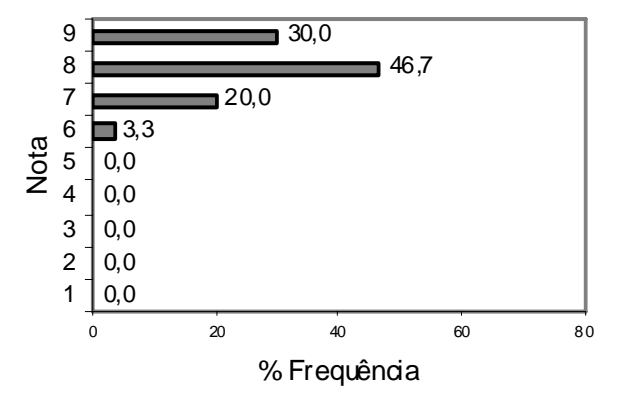

Questão 8 - Avaliação da seqüência lógica na apresentação dos módulos

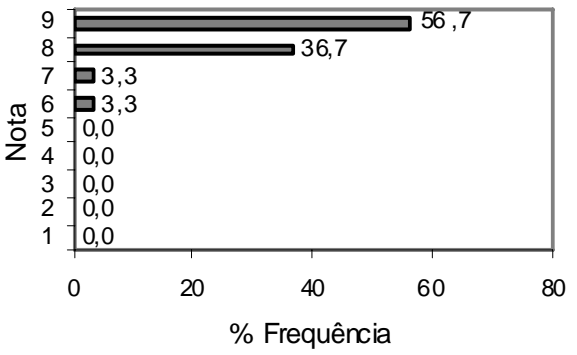

Questão 10 - Avaliação da adaptação do mutlimídia ao público alvo

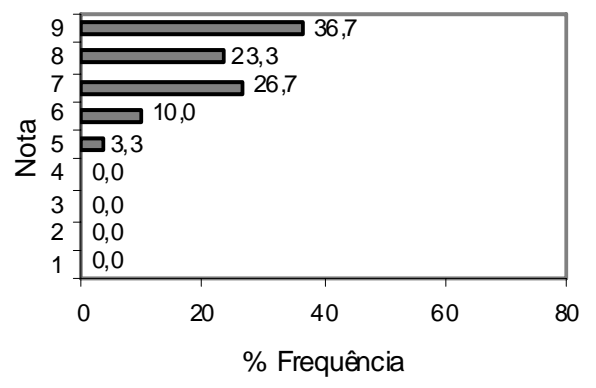

\section{QUADRO 1 - PRINCIPAIS ASPECTOS POSITIVOS, NEGATIVOS E SUGESTÕES DOS AVALIADORES DO SOFTWARE MULTIMIIIDIA COALHO QUALITY}

\section{Aspectos positivos}

1. Trabalho interessante e muito bom. Parabéns pela iniciativa e trabalho exposto.

2. Considero o Software Multim ídia Coalho Quality muito interessante, simples de ser explorado e bastante didático. Acredito que, a partir deste, outros sistemas poderão ser aperfeiçcados, auxiliando a elaboração de produtos mais seguros.

3. Agregação de valor ao produto.

4. O Software Multimídia é muito bom e pode atingir seus objetivos.

5. Trabalho belíssimo e de grande utilidade. Parabéns.

Aspectos negativos

1 Não foram mencionados.

Sug estões

1. Inserir uma apresentação do multimídia definindo seus objetivos e público-alvo.

2. O Software Multimídia poderia ser utilizado em supermercados para esclarecer o consumidor como ocorre o processo de fabricação do queijo coalho.

3. Acrescentar foto de estábulo e tanque de resf riamento que também constituem fontes de contaminação do leite na fazenda.

4. Colocar o glossário em ordem alfabética e inserir uma opção para maximizar a tela.

5. Inserir informações de contatos com extensionistas ou técnicos (SAC ou telefone).

6. Inserir informação sobre a necessidade de instalação do programa Windows Flash Play para utilização do Software Multimídia. 
FIGURA 8 - PORCENTAGENS DE FREQUÊNCIAS DE NOTAS ATRIBUÍDAS ÀS QUESTÕES QUE AVALIARAM OS MÓDULOS DO SOFTWARE MULTIMÍDIA: 1) CUIDADOS HIGIÊNICOS NA OBTENÇÃO DE LEITE NA FAZENDA; 2) FATORES DE CONTAMINAÇÃO DO LEITE; 3) CONTROLE SANITÁRIO DO REBANHO LEITEIRO; 4) HIGIENIZAÇÃO DE EQUIPAMENTOS, UTENSÍLIOS E OUTROS; 5) IMPORTÂNCIA DO CONTROLE DE QUALIDADE EM QUEIJARIAS; E 6) PROTOCOLO DE FABRICAÇÃO DO QUEIJO COALHO

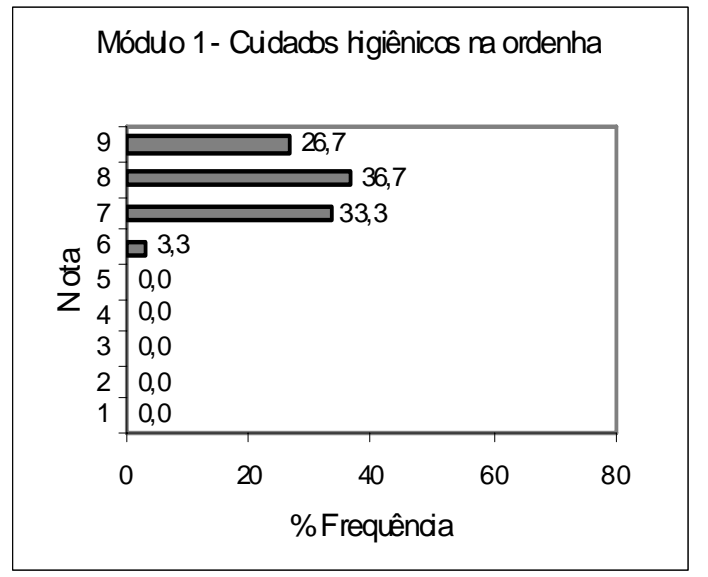

Módulo2 - Fortes de contaminação do leite

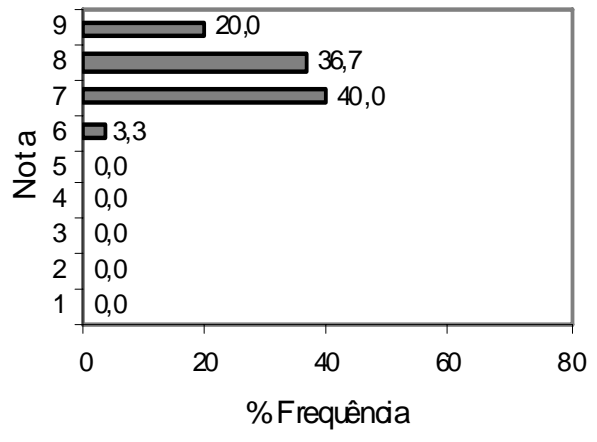

Mb́dulo 3 - Controle sanitário do rebarho leiteiro
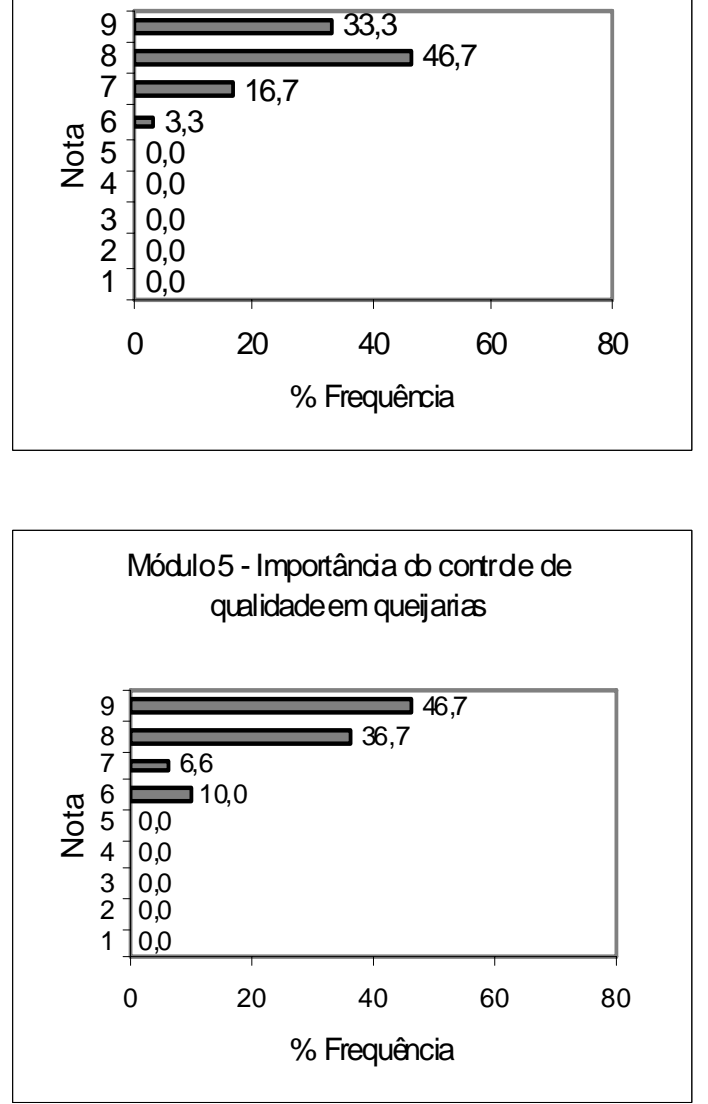

Módulo 6 - Protocolo de fabricação do queijo C calho

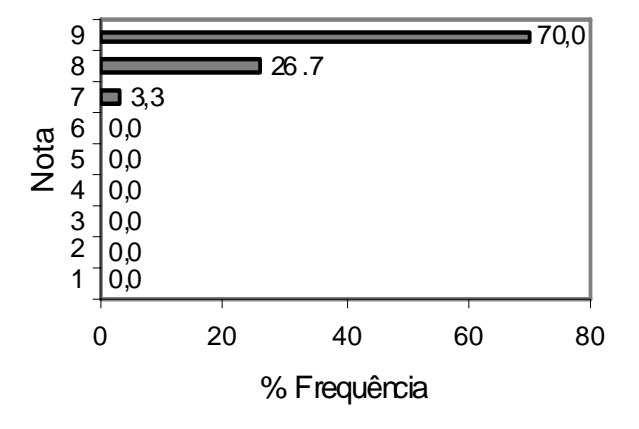



DO QUEIJO COALHO; 8) PLANTA BAIXA DE UMA FÁBRICA DE QUEIJO;

\section{9) MÓDULO DE APOIO}

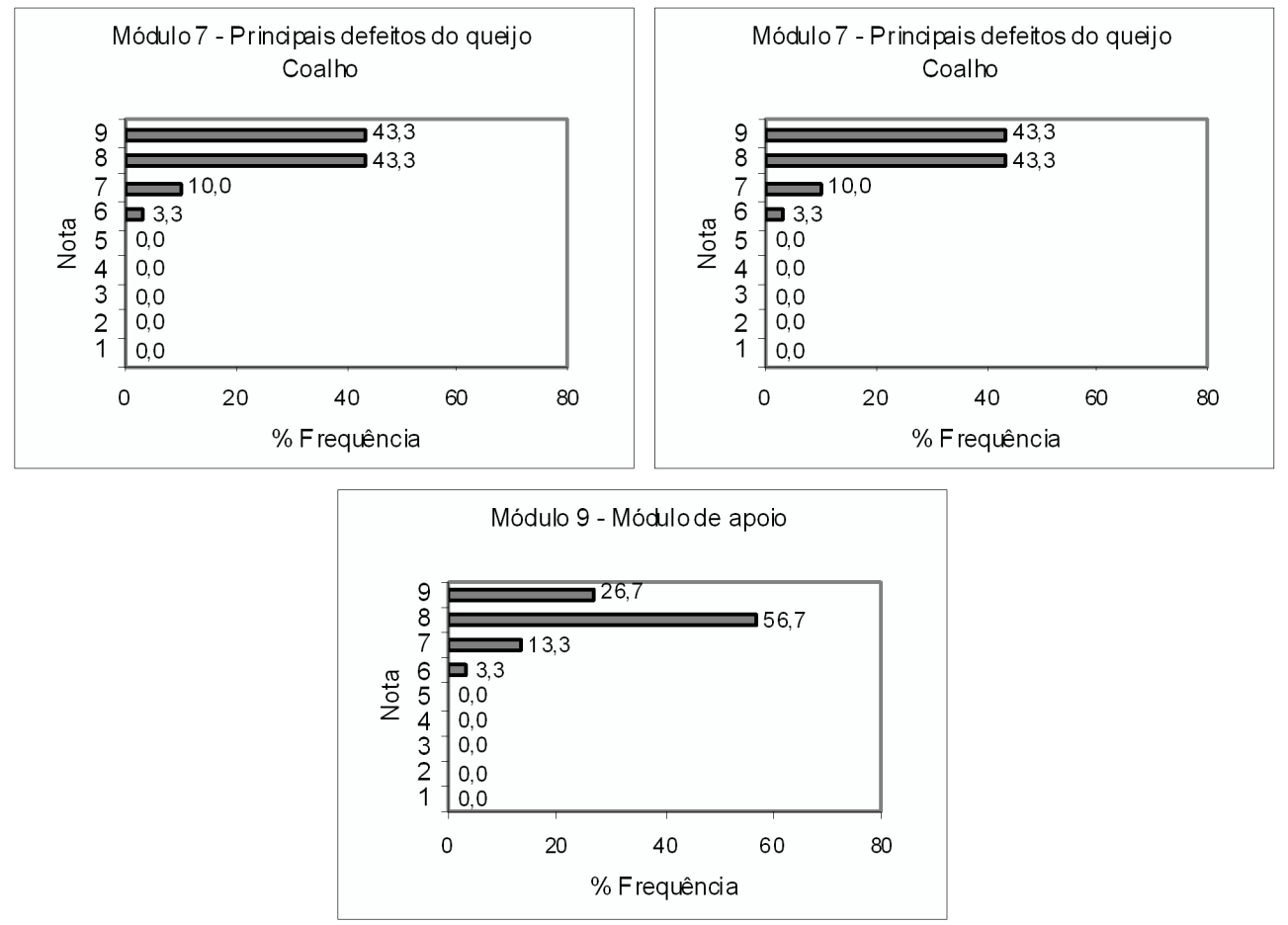

\section{TABELA 1 - MODA, MÁXIMO E MÍNIMO DAS NOTAS ATRIBUÍDAS À INTERFACE, AO CONTEÚDO E AOS MÓDULOS DO SOFTWARE MULTIMÍDIA COALHO QUALITY}

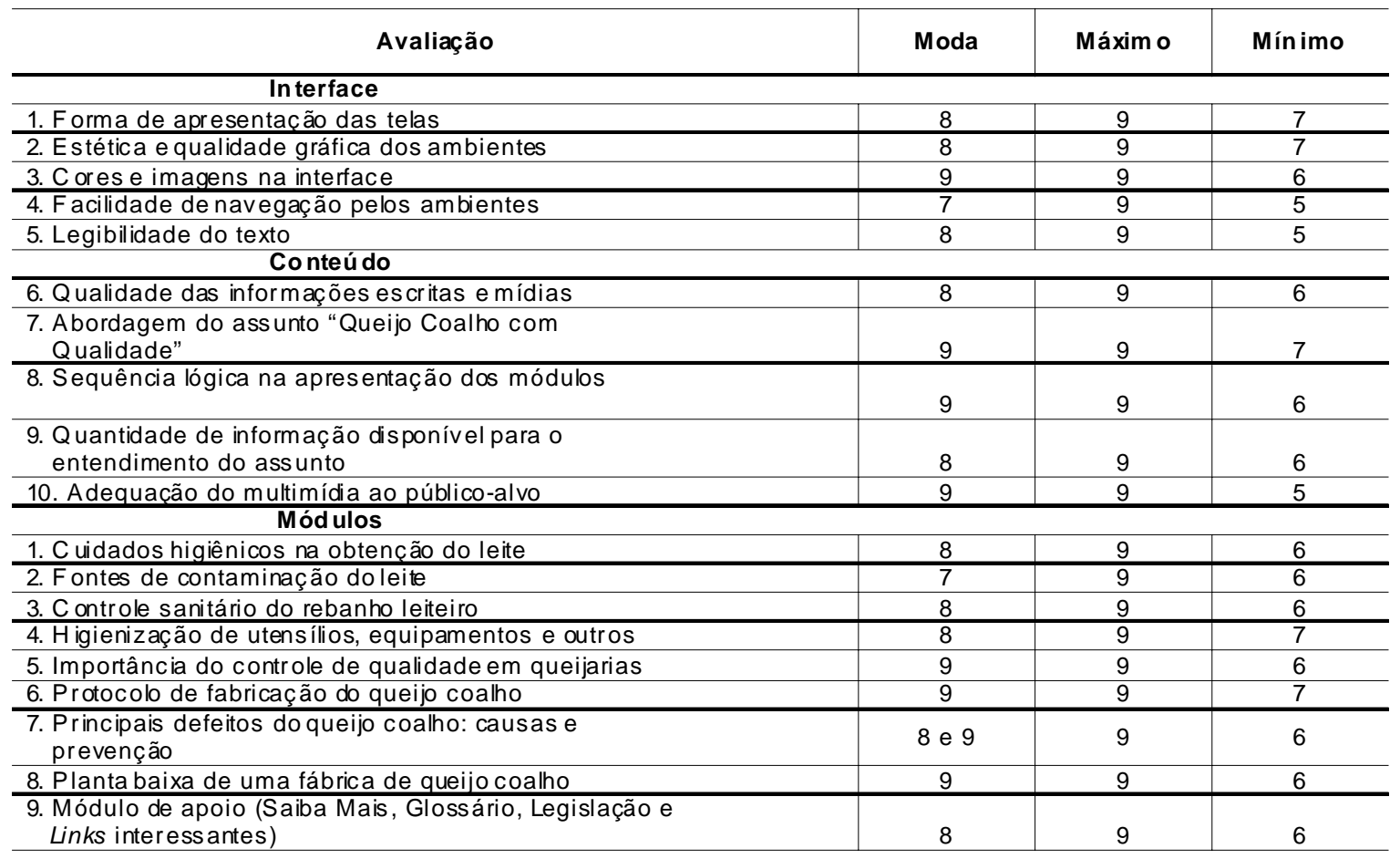

Nota: As notas seguiram a classificação de acordo com a Escala Hedônica. 
$\mathrm{Na}$ Tabela 1, as questões 6 e 9, referentes à qualidade e quantidade das informações disponíveis, respectivamente, para o entendimento do assunto tiveram como moda a nota 8 ("muito bom"). As questões 7, 8 e 10, que abordaram respectivamente os assuntos "queijo coalho com qualidade", sequência lógica na apresentação dos módulos e adequação do multimídia ao públicoalvo, obtiveram como moda a nota 9 , alcançando o conceito "extremamente bom" pela escala adotada neste trabalho.

Nesta avaliação, permitiu-se também classificar os 9 módulos do multimídia de acordo com a moda das notas dadas pelos 30 avaliadores. Os módulos 1 e 6, considerados os mais importantes do multimídia, foram classificados como "muito bom" e "extremamente bom", por receberem a maior frequência das notas 8 e 9, respectivamente. Os módulos 3, 4 e 9 foram classificados como "muito bom" pelos avaliadores. Os módulos 5, 6 e 8, respectivamente importância do controle de qualidade em queijarias, protocolo de fabricação e planta baixa de uma fábrica de queijo coalho, obtiveram o conceito "extremamente bom", por receberem em maior frequência a nota 9.0 módulo 7, que aborda as principais causas de defeitos e prevenções em queijos, foi considerado pelos avaliadores como "muito bom" e/ou "extremamente bom".

\section{CONCLUSÃO}

O software multimídia Coalho Quality foi considerado pelos avaliadores como ferramenta capaz de facilitar a aquisição de conhecimentos para a produção de leite e de queijo coalho regional com segurança alimentar.

O software multimídia pode ser utilizado pelo público-alvo como valiosa ferramenta de treinamento por facilitar a difusão de conhecimentos e informações de técnicos especialistas, possibilitando ainda a difusão do conhecimento para pessoas não especialistas em regiões brasileiras longínquas.

\section{ABSTRACT \\ SYSTEM MULTIMEDIA OF SUPPORT TO THE DECISION IN THE PRODUCTION OF MILK AND COALHO CHEESE WITH ALIMENTARY SECURITY}

The purpose of this work was to make available a System Multimedia of support to the decision in the production of milk and cheese type Coalho with alimentary security, in order to have quality improvement in products of small cheese factories of Northeast region of Brazil. This system is composed of a software, called Coalho Quality, which was evaluated by 30 evaluators and data were analyzed by descriptive statistic method, taking in consideration frequencies and percentages of the scores given to each attribute judged by evaluators. It was concluded that the software Multimedia Coalho Cheese can be used as a valuable tool of training by facilitate knowledge and information diffusion of technician specialists. Moreover, it makes possible the diffusion of the knowledge for non specialists, in other regions of Brazil.

KEY-WORDS: SYSTEM MULTIMEDIA; DECISORY PROCESS; CHEESE TIPE COALHO; ALIMENTARY SECURITY

\section{REFERÊNCIAS}

1 ANDRADE, N. J.; MACEDO, J. A. B. Higienização na indústria de alimentos. São Paulo: Livraria Varela, 1996. $182 \mathrm{p}$.

2 ANTUNES, M.A. Sistema multimídia de apoio à decisão em procedimentos de higiene, para unidades de alimentação e nutrição. 2003. 80 f. Dissertação (Mestrado em Ciência e Tecnologia de Alimentos), Universidade Federal de Viçosa, Viçosa, 2003.

3 BRANDÃO, S.C.C. Boas práticas de produção de leite cru. Revista dos Criadores, v. 67, n. 808, p. 20-23, set. 1997. 
4 BRABES, K.C.S. Detecção de Staphylococcus ssp. e suas enterotoxinas em leite proveniente de bovinos leiteiros com mastite. 1999. 77 f. Dissertação (Mestrado em Ciência e Tecnologia de Alimentos), Universidade Federal de Lavras, Lavras, 1999.

5 BRASIL. Ministério da Saúde. Portaria n. 1.428/93, de 26/11/1993. Regulamento técnico para inspeção sanitária de alimentos e as diretrizes para o estabelecimento de boas práticas de produção e de prestação de serviços na área de alimentos. Diário oficial [da] República Federativa do Brasil, BrasíliaDF, 02 maio 2003.

6 BRASIL. Ministério da Saúde. Portaria SVS-MS n. 326/97, de 30/07/1997. Estabelece os requisitos gerais (essenciais) de higiene e de boas práticas de fabricação para alimentos produzidos/fabricados para o consumo humano. Disponível em: www.anvisa.gov.br. Acesso: em 15/11/2009.

7 BRASIL. Ministério da Agricultura e Abastecimento. Portaria n. 368/97, de 4/09/1997. Regulamento técnico sobre as condições higiênico-sanitárias e de boas práticas de fabricação para estabelecimentos elaboradores/industrializadores de alimentos. Disponível em: www.anvisa.gov.br. Acesso em: 15 nov. 2009.

8 BRASIL. Ministério da Agricultura e Abastecimento. Portaria n. 46/98, de 10/02/1998. Manual genérico de procedimentos para APPCC em Indústrias de produtos de origem animal. Disponível em: www.anvisa.gov.br. Acesso em: 15 nov. 2009.

9 BRASIL. Ministério da Agricultura e do Abastecimento. Secretaria Nacional de Inspeção de Produtos de Origem Animal. Resolução n. 7, de 28/11/2000. Anexo I - Critérios de funcionamento e de controle da produção de queijarias, para seu relacionamento junto ao Serviço de Inspeção Federal. Diário Oficial [da] República Federativa do Brasil, Brasília-DF, 02 jan. 2001.

10 BRASIL. Ministério de Agricultura, Pecuária e Abastecimento. Secretaria de Defesa Agropecuária. Instrução Normativa n. 30/2001. Regulamento técnico de identidade e qualidade de queijo de coalho. Diário Oficial [da] República Federativa do Brasil, Brasília-DF, 26 jun. 2001.

11 BRASIL. Ministério da Saúde. Resolução RDC n. 275 de 21/10/2002. Anexo I - Regulamento técnico de procedimentos operacionais padronizados (POP) aplicados aos estabelecimentos produtores/ industrializadores de alimentos. Diário Oficial [da] República Federativa do Brasil, Brasília-DF, 06 nov. 2002.

12 BRESSAN, M. Práticas de manejo sanitário em bovinos de leite. In: CONTROLE sanitário dos rebanhos de leite. Juiz de Fora: Embrapa Gado de Leite Área de Comunicação Empresarial, 2000. p. 59- 65.

13 BRITO, J.R.F. Prepare-se para o parâmetro de qualidade. Revista Mundo do Leite, São Paulo, n. 2, p.3031, ago. 2002.

14 CAVALCANTE, J.F.M.; SILVA, R.F.N.; ANDRADE, N.J.; FURTADO, M.M.; CECON, P.R. Queijo coalho produzido com pool de culturas lácticas isoladas de leite cru da Região do Vale do Jaguaribe, Ceará, Brasil. Revista do Instituto de Laticínios Cândido Tostes, Juiz de Fora, v. 59, n. 339, p. 221-214, 2004.

15 CHAPAVAL, L.; PIEKARSKI, P.R.B. Leite de qualidade: manejo reprodutivo, nutricional e sanitário. ViçosaMG: Editora Aprenda Fácil, 2000. 195 p.

16 CHAVES, J.B.P.; SPROESSER, R.L. Práticas de laboratório de análise sensorial de alimentos e bebidas. 2. reimpr. Viçosa, MG: Editora UFV, 1999. 81 p. (Cadernos didáticos, 66).

17 CHIAVENATO, I. Administração de recursos humanos. 2.ed. São Paulo: Atlas, 1985. 375 p.

18 DRESCH, R.R.; JONG, E.V. Implantação da análise de perigos e pontos críticos de controle na fabricação de queijos. Higiene Alimentar, São Paulo, v. 16, n. 100, p. 30-36, set. 2002.

19 ESCOBAR, C.A.M.; LEUTHIER, S.; ANTUNES, G.; ALBUQUERQUE, R.C.L. Avaliação dos pontos críticos na produção de queijo de coalho em Pernambuco. Revista do Instituto de Laticínios Cândido Tostes, Juiz de Fora, v. 56, n. 321, p. 248-256, jul./ago. 2001.

20 FREITAS, L.H. Sistema especialista para diagnóstico de toxinfecções alimentares de origem bacteriana. 1995. 105 f. Dissertação (Mestrado em Ciência e Tecnologia de Alimentos), Universidade Federal de Viçosa, Viçosa, 1995. 
21 FURTADO, M.M. A qualidade do leite. In: AARTE e a ciência do queijo. São Paulo: Globo, 1991. p. 21-33. (Publicações Globo Rural).

22 FURTADO, M.M. Principais problemas dos queijos: causas e prevenção. São Paulo: Fonte Comunicações e Editora, 1999. 175 p.

23 MACÊDO, J.A. Sistema especialista para o controle e tratamento da água na indústria de alimentos. 1994. 105 f. Dissertação (Mestrado em Ciência e Tecnologia de Alimentos), Universidade Federal de Viçosa, Viçosa, 1994.

24 MAURER, H. Um panorama dos sistemas de hipermídia e multimídia. In: THALMANN, N. M.; THALMANN, D. (Org.). Mundos virtuais e multimídia. Rio de Janeiro: Livros Técnicos e Científicos, 1993. p. 1-15.

25 MORAIS, C.M.M. Processamento artesanal de queijo de coalho de Pernambuco: uma análise de perigos. 1995. 108 f. Dissertação (Mestrado em Nutrição), Universidade Federal de Pernambuco, Recife, 1995.

26 NEVES JR., L.T. Aplicação dos conceitos de educação à distância ao treinamento: um estudo de caso em uma rede de farmácias. 2002. 121 f. Dissertação (Mestrado em Engenharia de Produção), Universidade Federal de Santa Catarina, Florianópolis, 2002.

27 NASSU, R. T. et al. Diagnóstico das condições de processamento e caracterização físico-química de queijos regionais e manteiga no Rio Grande do Norte. Fortaleza: Embrapa Agroindústria Tropical, 2003.

28 NETO, L.G.G.; NEVES, M.V.O.; VELOSO, F.P.; PAIVA, R.M.B.; PENNA, C.F.A.M.; SENNA, M.J. Qualidade físico-química e microbiológica de queijo de coalho produzido no Brasil - revisão. Revista do Instituto de Laticínios Cândido Tostes, Juiz de Fora, v. 59, n. 339, p. 236-239, 2004.

29 PICININ, L.C.; CERQUEIRA, M.M.O.P.; SOUZA, M.R.; PENNA, C.F.A.M.; CAMARGOS, C.R.M. Diagnóstico de situação da qualidade da água de fazendas leiteiras de Minas Gerais. Revista do Instituto de Laticínios Cândido Tostes, Juiz de Fora, v. 56, n. 321, p. 301-310, jul./ago. 2001.

30 PINHEIRO, A.J.R.; MOSQUIM, M.C.A.V. Obtenção higiênica do leite. Viçosa-MG: Departamento de Tecnologia de Alimentos/Universidade Federal de Viçosa, 1995. p.10-21.

31 PINHEIRO, A.J.R.; SOUSA, J.G. Pequenos problemas, grandes conseqüências. Revista Leite e Derivados, São Paulo, v.12, n. 77, p. 18-34, mai./jun. 2004.

32 PIRES, E.F; MORAIS, C.M.M; SILVA, J.A; CARVALHO, R.O.C. Queijo de coalho: perfil industrial. Recife: SEBRAE/PE, 1994. p. 44.

33 POZZA, E.A. Desenvolvimento de sistemas especialistas e redes neuronais e suas aplicações em Fitopatologia. 1998. 153 f. Tese (Doutorado em Fitopatologia), Universidade Federal de Viçosa, Viçosa, 1998.

34 SANTOS, S.L.M. Sistema de apoio à decisão em colheita florestal. Viçosa, MG. 2000, 94 f. Tese (Doutorado em Ciência Florestal), Universidade Federal de Viçosa, Viçosa, 2000.

35 SENAI. Ferramentas para implantação do sistema APPCC. 2. ed. Brasília: CNI/SENAI, 1999. CDROM.

36 SENAI/PAS. Programa Alimentos Seguros. Ferramentas para implantação do sistema APPCC. Brasília: CNI/SENAI, 2002. CD-ROM.

37 SENA, M.J. Perfil epidemiológico, resistência à antibióticos e aos conservantes nisina e sistema lactoperoxidase de Staphylococcus ssp. isolados de queijos coalho comercializados em Recife-PE. 2000. 75 f. Tese (Doutorado em Medicina Veterinária), Universidade Federal de Minas Gerais, Belo Horizonte, 2000.

38 SPROESSER, R.L. Utilização de técnicas de inteligência artificial no planejamento da produção e controle da qualidade na indústria de laticínios. 1991. 121 f. Dissertação (Mestrado em Ciência e Tecnologia de Alimentos), Universidade Federal de Viçosa, Viçosa, 1991. 
39 TESHIMA, E.; VIANA, A.C.; DE ASSIS, M. M. S.; FIGUEIREDO, H. M. Identidade e qualidade do queijo de coalho comercializado em Feira de Santana-BA. Revista do Instituto de Laticínios Cândido Tostes, Juiz de Fora, v. 59, n. 339, p. 194-197, jul../ago. 2004.

40 TROCHIM, W. M. K. Likert scaling. Disponível em: <http://www.trochim.human.cornell.edu//kb/scallic.htm>. Acesso em: 7 jul. 2003.

41 TRONCO, V.M. Manual para inspeção da qualidade do leite. 2. ed. Santa Maria-RS: Editora UFSM, 2003. $192 \mathrm{p}$.

42 YASSU, F.O queijo da Serra em busca de identidade. Revista Mundo do Leite, São Paulo, n. 4, p. 26-32, maio 2003.

\section{AGRADECIMENTOS}

À Coordenação de Aperfeiçoamento de Pessoal de Nível Superior (CAPES), à Universidade Estadual do Ceará e ao Departamento de Tecnologia de Alimentos da Universidade Federal de Viçosa - MG pelo suporte financeiro e técnico, respectivamente. 